\title{
Addition of milk fat globule membrane-enriched supplement to a high-fat meal attenuates insulin secretion and induction of soluble epoxide hydrolase gene expression in the postprandial state in overweight and obese subjects
}

Elizabeth Beals ${ }^{1}$, S. G. Kamita ${ }^{2}$, R. Sacchi ${ }^{1}$, E. Demmer ${ }^{1}$, N. Rivera ${ }^{1}$, T. S. Rogers-Soeder ${ }^{1}$, E. R. Gertz ${ }^{3}$, M. D. Van Loan ${ }^{1,3}$, J. B. German ${ }^{4,5}$, B. D. Hammock ${ }^{2}$, J. T. Smilowitz ${ }^{4,5}$ and A. M. Zivkovic ${ }^{1,4} *$

${ }^{1}$ Department of Nutrition, University of California, Davis, CA, USA

${ }^{2}$ Department of Entomology, University of California, Davis, CA, USA

${ }^{3}$ US Department of Agriculture/Agricultural Research Service Western Human Nutrition Research Center, Davis, CA, USA

${ }^{4}$ Foods for Health Institute, University of California, Davis, CA, USA

${ }^{5}$ Department of Food Science \& Technology, University of California, Davis, CA, USA

(Received 12 August 2018 - Final revision received 7 March 2019 - Accepted 8 March 2019)

Journal of Nutritional Science (2019), vol. 8, e16, page 1 of 14

doi:10.1017/jns.2019.11

Abstract

CVD and associated metabolic diseases are linked to chronic inflammation, which can be modified by diet. The objective of the present study was to determine whether there is a difference in inflammatory markers, blood metabolic and lipid panels and lymphocyte gene expression in response to a high-fat dairy food challenge with or without milk fat globule membrane (MFGM). Participants consumed a dairy product-based meal containing whipping cream (WC) high in saturated fat with or without the addition of MFGM, following a $12 \mathrm{~h}$ fasting blood draw. Inflammatory markers including IL-6 and C-reactive protein, lipid and metabolic panels and lymphocyte gene expression fold changes were measured using multiplex assays, clinical laboratory services and TaqMan real-time RT-PCR, respectively. Fold changes in gene expression were determined using the Pfaffl method. Response variables were converted into incremental AUC, tested for differences, and corrected for multiple comparisons. The postprandial insulin response was significantly lower following the meal containing MFGM $(P<0 \cdot 01)$. The gene encoding soluble epoxide hydrolase (EPHX2) was shown to be more up-regulated in the absence of MFGM $(P=0.009)$. Secondary analyses showed that participants with higher baseline cholesterol:HDL-cholesterol ratio (Chol:HDL) had a greater reduction in gene expression of cluster of differentiation 14 (CD14) and lymphotoxin $\beta$ receptor (LTBR) with the WC+MFGM meal. The protein and lipid composition of MFGM is thought to be anti-inflammatory. These exploratory analyses suggest that addition of MFGM to a high-saturated fat meal modifies postprandial insulin response and offers a protective role for those individuals with higher baseline Chol:HDL.

Key words: Milk fat globule membrane: Postprandial inflammation: Saturated fat: Cytokines: Metabolic syndrome: Overweight: Inflammatory markers

CVD and type 2 diabetes mellitus (T2DM) are both linked with chronic inflammation ${ }^{(1)}$. Diet plays a major role in influencing inflammation at the vascular wall and in peripheral tissues, where atherosclerosis and insulin resistance can $\operatorname{occur}^{(2,3)}$. Obesity is another major contributor to chronic inflammation and increases an individual's risk for

Abbreviations: ARA, arachidonic acid; CD14, cluster of differentiation 14; Chol:HDL, cholesterol:HDL-cholesterol ratio; CRP, C-reactive protein; EPHX2, soluble epoxide hydrolase; iAUC, incremental AUC; LBP, lipopolysaccharide binding protein; LPS, lipopolysaccharide; LTBR, lymphotoxin $\beta$ receptor; MetS, metabolic syndrome; MFGM, milk fat globule membrane; SAA, serum amyloid A; sEH, soluble epoxide hydrolase; T2DM, type 2 diabetes mellitus; WC, whipping cream.

* Corresponding author: Dr Angela Zivkovic, fax +1 530752 8966, email amzivkovic@ucdavis.edu 
hypertension, dyslipidaemia, hyperglycaemia and T2DM. Together, these co-morbidities are termed the metabolic syndrome (MetS), and are mediated by inflammatory processes in the body ${ }^{(4-7)}$. It has been estimated that $35 \%$ of adults have traits of the MetS, a figure that jumps to $50 \%$ in adults over the age of 60 years ${ }^{(8)}$. The MetS increases the risk of T2DM, which is associated with increased risk of retinopathy, infection and peripheral neuropathy, which can result in amputations and blindness ${ }^{(7,9-12)}$.

The magnitude of the postprandial (or immediately following a meal) inflammatory response plays a role in the progression of CVD and exacerbates the risk of developing the MetS in individuals with existing chronic inflammation ${ }^{(13)}$. In Western societies, most of the day is spent in the postprandial period, with only a few hours in the early morning spent in the fasted state ${ }^{(14-16)}$. Risk for chronic metabolic disease may be more apparent by looking at the inflammatory response following a meal, as opposed to looking at fasting markers of inflammation ${ }^{(14)}$. Furthermore, meal composition is an important determinant of postprandial macronutrient metabolism and inflammation. Saturated fat from any dietary source, including dairy products, was once thought to be a major contributor to CVD risk. A few reviews summarising numerous randomised controlled trials and epidemiological studies showed that while consumption of dairy products may improve certain clinical biomarkers that are associated with CVD risk, there is not enough evidence to state whether consumption of dairy products is neutral or beneficial to overall CVD risk ${ }^{(17-19)}$. Additionally, differences exist in clinical end points for high-fat, low-fat, fermented and total dairy products $^{(18,20,21)}$. The fatty acid composition and other bioactive molecules in conjunction with the saturated fat may alter the overall physiological response. Milk fat globule membrane (MFGM) is a component of dairy foods found in the lipid fraction that contains phospholipids, sphingolipids, branchedchain amino acids and oligosaccharides that have been shown to be anti-inflammatory and potentially cardioprotective ${ }^{(1)}$. Following dairy food processing, the native MFGM structure is disrupted and its components may be found at varying levels in certain dairy products, such as buttermilk or cream, but some proteins derived from MFGM have been found in skimmed milk ${ }^{(22)}$. Furthermore, the mammalian species the milk is derived from, their diets, and the subsequent levels of different fatty acids may influence the processing dynamics of $\mathrm{MFGM}^{(22,23)}$.

Individuals are highly variable in terms of diet, genetic composition and metabolic activity and are at different stages of the atherosclerosis continuum, thus making it difficult to come up with established cut-offs to describe postprandial inflammation $^{(24)}$. Furthermore, clinical markers of lipid metabolism have focused on lipid levels in the fasting state, whereas most of an individual's day is spent in the postprandial state ${ }^{(16)}$. Numerous studies have measured postprandial inflammation; however, these studies vary in the postprandial blood collection times, the type of markers measured and the fatty acid composition of the test meal ${ }^{(25-27)}$. Studies that collected the same markers have shown contrasting results ${ }^{(13)}$. It is therefore reasonable to argue that postprandial inflammation is not altogether understood. Fortunately, the measurement of postprandial markers of inflammation as opposed to fasting markers is rapidly gaining favour as a means of studying CVD risk, especially the postprandial handling of $\mathrm{SFA}^{(28,29)}$. Studies have shown that fatty acids derived from dairy products may have a beneficial effect on postprandial inflammation, and that this beneficial effect may stem from the bioactive membrane components of $\operatorname{MFGM}^{(20)}$. Therefore, the present study sought to test whether addition of MFGM to a meal high in saturated fat derived from cream could mitigate the postprandial inflammation experienced in a sample of non-diabetic overweight and obese adults. The present randomised, crossover study measured the plasma inflammatory responses, lipid and metabolic panels and lymphocyte gene expression from baseline to $6 \mathrm{~h}$ postprandially.

\section{Materials and methods}

All of the clinical study parameters have been described previously in Demmer et al. ${ }^{(13)}$.

\section{Participants}

A total of thirty-six participants (seventeen men and nineteen women) between 18 and 65 years of age participated in the study. Participants were recruited from Davis, Sacramento, and the surrounding Northern California regions. The inclusion criteria included an overweight BMI (25-29.9 kg/m²), and at least two MetS traits according to the American Heart Association (AHA) definition, or an obese BMI (30$39.9 \mathrm{~kg} / \mathrm{m}^{2}$ ) and any number of MetS traits. Traits of the MetS include a waist circumference $>40$ inches $(>102 \mathrm{~cm})$ for men and $>35$ inches $(>89 \mathrm{~cm})$ for women; fasting plasma TAG $\geq 150 \mathrm{mg} / \mathrm{dl} \quad(\geq 1.70 \mathrm{mmol} / \mathrm{l})$; fasting plasma HDL-cholesterol $<40 \mathrm{mg} / \mathrm{dl}(<1.04 \mathrm{mmol} / \mathrm{l})$ for men and $<50 \mathrm{mg} / \mathrm{dl} \quad(<1.30 \mathrm{mmol} / \mathrm{l})$ for women; blood pressure $\geq 130 / 85 \mathrm{mmHg}$; and fasting glucose $\geq 100 \mathrm{mg} / \mathrm{dl}(\geq 5.56$ $\mathrm{mmol} / \mathrm{l})^{(30)}$. The AHA definition of the MetS includes having at least three of the previous parameters.

Exclusion criteria included diagnosis of an immune-related disease, gastrointestinal disorder, T2DM, eating disorder, allergy to the provided study foods, cancer, pregnancy or lactation, a greater than $10 \%$ change in body weight within the previous 6 months, or poor vein accessibility as evaluated by the study phlebotomist. Additional exclusionary criteria included use of a weight loss medication, daily use of a nonsteroidal anti-inflammatory drug, anti-inflammatory supplement, corticoid steroid, tobacco, a change in hormonal birth control use within the previous 6 months, or initiation of statins within the previous 3 months. Additionally, initiation of an exercise programme within the previous 6 months or having plans to become pregnant within 6 months were exclusionary criteria. Dietary exclusionary criteria included consumption of $>1$ servings of fish per week, $>14 \mathrm{~g}$ fibre per $1000 \mathrm{kcal}(4184$ $\mathrm{kJ}$ ) per $\mathrm{d},<16: 1$ ratio of total dietary $n-6: n-3,>1 \%$ daily energy in the form of trans-fats, and a vegetarian diet pattern.

Eligibility was determined using health history questionnaires that asked potential participants about their health history, diet 
and medications. During the screening visit, anthropometric measurements (height, weight and waist circumference) were taken, along with a fasting blood sample to evaluate blood lipids and glucose to determine MetS status. Details of recruitment, screening and enrolment can be found in Fig. 1.

This study was conducted according to the guidelines laid down in the Declaration of Helsinki and all procedures involving human subjects/patients were approved by the Institutional Review Board of the University of California, Davis. Written informed consent was obtained from all participants. The study was registered at ClinicalTrials.gov as NCT01811329.

\section{Study design}

Participants were randomised to consume two isoenergetic test meals in a double-blinded, cross-over design. A high-fat whipping cream (WC) meal was compared with a high-fat WC meal with MFGM (WC+MFGM) added. The meals were each consumed in the morning, separated by a 1 - to 2 -week-long washout period to avoid carryover effects. Consumption of antiinflammatory supplements, non-steroidal anti-inflammatory drugs or alcohol was not permitted for the $72 \mathrm{~h}$ preceding the study visit day. Additionally, seafood consumption and vigorous exercise in the $24 \mathrm{~h}$ preceding the study visit day were not permitted to avoid confounding changes in inflammatory markers. Compliance was assessed using a 1-d food record representative of the previous $24 \mathrm{~h}$. Analysis of the diet records was performed using the Nutrition Data System for Research (NDSR; University of Minnesota).

Each study visit day, participants arrived at the Western Human Nutrition Research Center following a 10-12 h fast. The participants then completed the 24-h diet record and a modified gastrointestinal questionnaire ${ }^{(31)}$. The $0 \mathrm{~h}$ fasted blood sample was then collected by venepuncture. Anthropometrics, including blood pressure, heart rate, waist circumference and weight were measured. The test meal was consumed within 20 min, and postprandial blood draws were collected at 1, 3 and $6 \mathrm{~h}$ postprandially, as determined from previous postprandial clinical trials observing postprandial inflammation following a high-fat test meal ${ }^{(32)}$. Following the test meal, exercise or consumption of any other food was not permitted for the remainder of the study visit day. Bottled water was allowed, as was leaving the facility by car between time points.

\section{Dietary challenges}

The test meals on both study visit days included either a WC or WC+MFGM smoothie, along with a thin slice of bagel with strawberry preserves. The smoothie contained deionised water, whey protein isolate, raspberry sorbet and anhydrous cream composed of $99.8 \%$ dairy fat ${ }^{(33)}$. The WC+MFGM smoothie contained the ingredients previously mentioned, as well as 10 $\%$ by weight BPC50, a proprietary cream-derived complex milk lipid fraction powder ( $\beta$ serum concentrate) supplied by the Fonterra Co-operative Group Ltd (New Zealand). BPC50 contains $(\% \mathrm{w} / \mathrm{w}): 52 \%$ protein, which includes $13.2 \%$ membrane-derived, $6.6 \%$ lactose and $36.2 \%$ total fat (22.5\% TAG and $13.7 \%$ phospholipids), $0.63 \%$ gangliosides (GD3) and $5.2 \% \mathrm{ash}^{(13)}$. Fatty acid binding protein, butyrophilin, lactadherin, adipophilin and xanthine oxidase and mucin are the proteins of highest abundance in BPC50. More information on the test meal ingredients can be found in Table 1. Following consumption of the test meal, participants were asked to rinse their smoothie cups and to drink the rinse water.

The energy content of the meals was formulated to provide $40 \%$ of each participant's daily energy intake, calculated using the National Academy of Sciences equation from the Institute of Medicine Dietary Reference Intake ${ }^{(34)}$. The Baecke Physical Activity Questionnaire was used to determine physical activity level ${ }^{(35)}$. The WC and WC+MFGM meals were formulated to vary less than $0.2 \%$ in macronutrients. Each meal provided each participant approximately $55 \%(49-87 \mathrm{~g})$ fat, $30 \%$ (61-107 g) carbohydrate and 15\% (31-55 g) protein of total energy intake, scaled to each participant's daily energy need. The addition of MFGM replaced $31 \%$ of the fat in each meal, or $34 \%$ of total energy. The nutrient composition of the test meals was estimated using the NDSR.

\section{Blood analyses}

Whole blood was drawn by venepuncture at baseline $(0 \mathrm{~h})$, and at 1,3 and $6 \mathrm{~h}$ postprandially. Red-or gold-top tubes were left to clot at room temperature for $30 \mathrm{~min}$ before being centrifuged at $1300 \mathrm{~g}$ at $4^{\circ} \mathrm{C}$ for $10 \mathrm{~min}$. Whole blood EDTA tubes were placed on ice immediately following the blood draw and were centrifuged within $30 \mathrm{~min}$ at $1300 \mathrm{~g}$ at $4^{\circ} \mathrm{C}$ for $10 \mathrm{~min}$. All serum and plasma tubes were kept on ice during aliquoting, and subsequently placed at $-80^{\circ} \mathrm{C}$ until analysis.

\section{Inflammatory markers}

Inflammatory markers assessed from serum included cytokines (IL-10, IL-1 $\beta$, IL-2, IL-4, IL-6, IL-8, TNF- $\alpha$ and monocyte chemoattractant protein-1) and vascular injury molecules (C-reactive protein (CRP), serum amyloid A (SAA), soluble intercellular adhesion molecule and soluble vascular adhesion molecule). The concentration of IL-18 was assessed from plasma. Analyses were performed using a Multi Spot ELISA kit as recommended by the manufacturer, Meso Scale Discovery (SECTOR Imager 2400). Plates came pre-coated with antibodies and were incubated with $25-50 \mu \mathrm{l}$ of serum or plasma. Labelled detection antibodies were assessed following a washing step. Protein quantification was determined through detection of light emitted by the labelled antibodies upon electrical stimulation. To determine the postprandial inflammatory response, the incremental AUC (iAUC) was calculated for each marker, from $1 \mathrm{~h}$ postprandially to $6 \mathrm{~h}$ postprandially.

\section{Metabolic parameters}

Whole blood was collected in a $3.5 \mathrm{ml}$ serum-separating gold-top tube, allowed to clot at room temperature and centrifuged at $1300 \mathrm{~g}$ for $20 \mathrm{~min}$. The samples were then assessed for glucose 

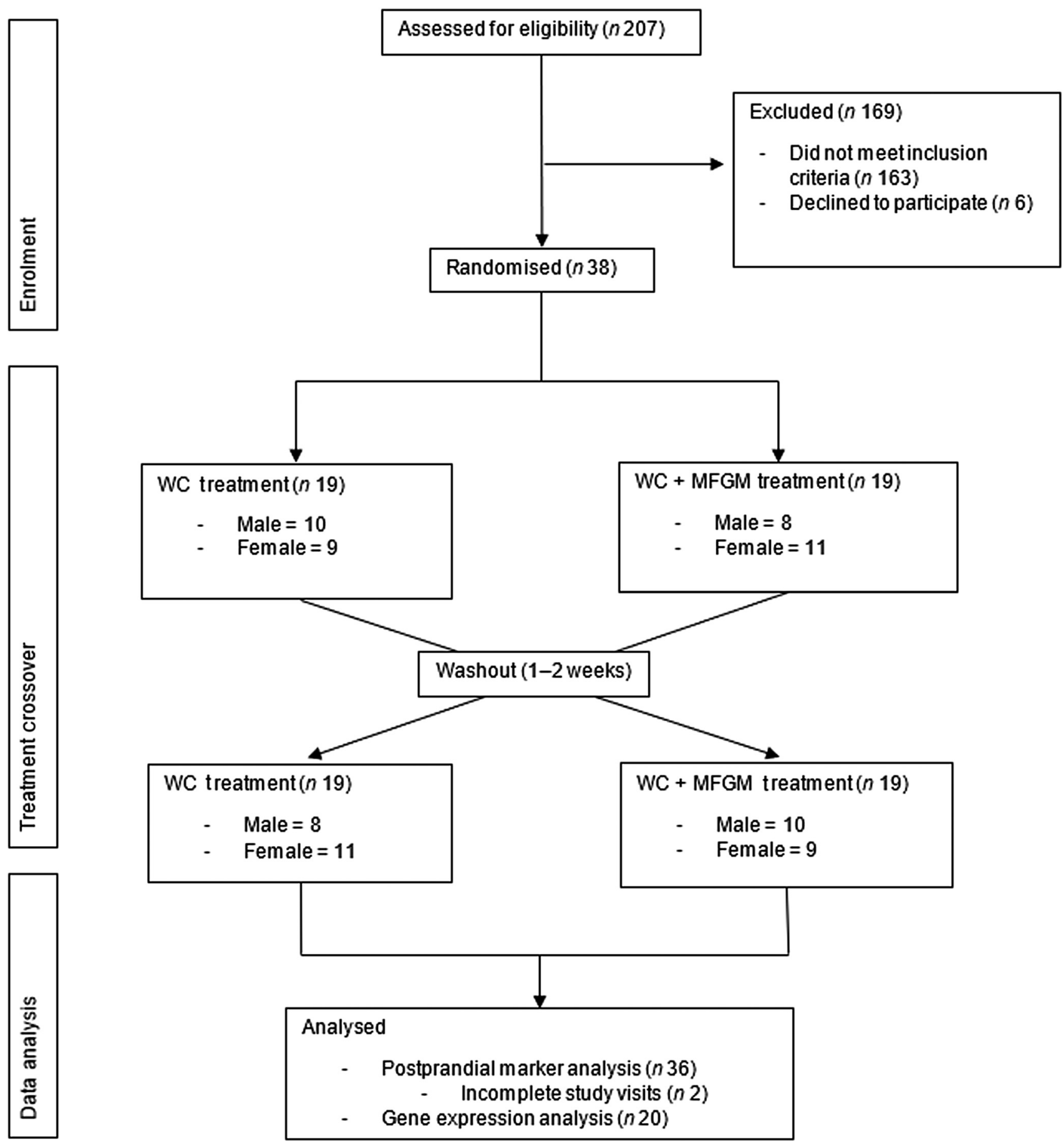

Fig. 1. Consolidated Standards of Reporting Trials (CONSORT) diagram of the randomised crossover trial showing enrolment, treatment allocation and analysis of participants. WC, whipping cream; WC+MFGM, whipping cream + milk fat globule membrane.

levels and a lipid panel at the baseline, $1 \mathrm{~h}, 3 \mathrm{~h}$ and $6 \mathrm{~h}$ time points, and assessed for insulin levels at the baseline, $1 \mathrm{~h}$ and $3 \mathrm{~h}$ time points. Sample analysis was carried out at the University of California Davis Medical Center Pathology Laboratory.

\section{Clinical characteristics}

Participant height was taken at enrolment using a wallmounted stadiometer (Ayrton Stadiometer Model S100; Ayrton Corporation). At the beginning of each study visit, body weight and waist circumference were taken in duplicate. Participant body weight was collected using the Calibrates 6002 Wheelchair Scale (Scaletronix). Waist circumference was measured using QM2000 Measure Mate (QuickMedical). A member of the study team measured participant waist circumference midway between the lateral lower rib and the iliac crest while standing. At baseline and at each postprandial time point, blood pressure and heart rate were measured using the GE Instruments Carescape V100 with Critikon Dura-cuff for adults or large adults ${ }^{(13)}$. 
Table 1. Test meal composition (Mean values and standard deviations)

\begin{tabular}{|c|c|c|c|c|}
\hline \multirow[b]{2}{*}{ Meal component } & \multicolumn{2}{|c|}{ WC } & \multicolumn{2}{|c|}{ WC+MFGM } \\
\hline & Mean & SD & Mean & SD \\
\hline \multicolumn{5}{|l|}{ Energy } \\
\hline kcal & $1094 \cdot 2$ & 187.5 & $1094 \cdot 2$ & $187 \cdot 7$ \\
\hline kJ & $4578 \cdot 1$ & 784.5 & $4578 \cdot 1$ & $785 \cdot 3$ \\
\hline Total fat (g) & 68.0 & 11.6 & 67.9 & 11.7 \\
\hline Fat (\% total energy) & $55 \cdot 9$ & 0.0 & 55.9 & 0.0 \\
\hline Total carbohydrate (g) & 83.5 & $14 \cdot 3$ & 84.0 & 14.4 \\
\hline Carbohydrates (\% total energy) & 30.5 & 0.0 & $30 \cdot 7$ & 0.0 \\
\hline Total protein (g) & $42 \cdot 9$ & $7 \cdot 3$ & 43.4 & 7.4 \\
\hline Protein (\% total energy) & $15 \cdot 7$ & 0.0 & $15 \cdot 9$ & 0.0 \\
\hline Total SFA (g) & 41.6 & 7.1 & $40 \cdot 6$ & $7 \cdot 0$ \\
\hline SFA (\% total energy) & $34 \cdot 2$ & 0.0 & 33.4 & 0.0 \\
\hline Total MUFA (g) & 19.4 & $3 \cdot 3$ & $19 \cdot 3$ & 3.3 \\
\hline MUFA (\% total energy) & $16 \cdot 0$ & 0.0 & $15 \cdot 8$ & 0.0 \\
\hline Total PUFA $(\mathrm{g})^{\star}$ & 3.2 & 0.6 & 3.7 & 0.6 \\
\hline PUFA (\% total energy) ${ }^{*}$ & $2 \cdot 6$ & 0.0 & 3.0 & 0.0 \\
\hline $\begin{array}{l}\text { SFA } 4 \text { : } 0 \text { (butyric acid) }(\% \text { total } \\
\text { weight) }{ }^{*}\end{array}$ & 0.4 & 0.0 & 0.3 & 0.0 \\
\hline $\begin{array}{l}\text { SFA } 6: 0 \text { (caproic acid) (\% total } \\
\text { weight) }\end{array}$ & 0.3 & 0.0 & 0.2 & 0.0 \\
\hline $\begin{array}{l}\text { SFA } 8 \text { : } 0 \text { (caprylic acid) (\% total } \\
\text { weight)* }\end{array}$ & $0 \cdot 1$ & 0.0 & 0.1 & 0.0 \\
\hline $\begin{array}{l}\text { SFA } 10: 0 \text { (capric acid) (\% total } \\
\text { weight) }\end{array}$ & 0.3 & 0.0 & 0.3 & 0.0 \\
\hline $\begin{array}{l}\text { SFA } 12 \text { : } 0 \text { (lauric acid) (\% total } \\
\text { weight) }\end{array}$ & 0.4 & 0.0 & 0.3 & 0.0 \\
\hline $\begin{array}{l}\text { SFA } 14 \text { : } 0 \text { (myristic acid) (\% total } \\
\text { weight) }\end{array}$ & 1.3 & 0.0 & $1 \cdot 1$ & 0.0 \\
\hline $\begin{array}{l}\text { SFA } 16 \text { : } 0 \text { (palmitic acid) (\% of total } \\
\text { weight) }\end{array}$ & 3.5 & 0.0 & 2.9 & 0.0 \\
\hline $\begin{array}{l}\text { SFA } 18 \text { : } 0 \text { (stearic acid) (\% total } \\
\text { weight) }\end{array}$ & 1.6 & 0.0 & 1.4 & 0.0 \\
\hline $\begin{array}{l}\text { MUFA } 16: 1 \text { (palmitoleic acid) (\% } \\
\text { total weight)* }\end{array}$ & 0.3 & 0.0 & 0.2 & 0.0 \\
\hline $\begin{array}{l}\text { MUFA } 18: 1 \text { (oleic acid) (\% of total } \\
\text { weight) }\end{array}$ & 3.4 & 0.0 & $2 \cdot 9$ & 0.0 \\
\hline $\begin{array}{l}\text { PUFA } 18 \text { : } 2 \text { (linoleic acid) (\% total } \\
\text { weight) }\end{array}$ & 0.4 & 0.0 & 0.4 & 0.0 \\
\hline $\begin{array}{l}\text { PUFA } 18 \text { : } 3 \text { (linolenic acid) }(\% \text { total } \\
\text { weight) })^{\star}\end{array}$ & 0.2 & 0.0 & 0.2 & 0.0 \\
\hline
\end{tabular}

WC, whipping cream; MFGM, milk fat globule membrane.

* Significant total difference by weight $(P<0.05)$.

\section{Lymphocyte isolation}

Following centrifugation, the plasma layer was aliquoted and used for inflammatory marker analyses. The lymphocyte layer was isolated and transferred to a tube containing $2 \mathrm{ml}$ PBS. The lymphocyte-PBS solution was carefully transferred to a tube containing Ficoll-Paque before being centrifuged at $450 \mathrm{~g}$ for $10 \mathrm{~min}$. The cells were then resuspended in $1 \mathrm{ml}$ PBS and centrifuged at $1000 \mathrm{~g}$ in a microfuge for $1 \mathrm{~min}$ at $4^{\circ} \mathrm{C}$. Following centrifugation, the cells were resuspended in $400 \mu \mathrm{l}$ of RNAlater (Ambion) and stored overnight at $4^{\circ} \mathrm{C}$ before being transferred to a $-80^{\circ} \mathrm{C}$ freezer until lymphocyte quantification and RNA extraction were performed.

\section{Lymphocyte quantification}

The lymphocytes were kept frozen until cell counting was performed. An aliquot of the lymphocytes in RNAlater was 1:10 diluted with PBS pH 7.4 and counted using a haemocytometer under $200 \times$ magnification. Following quantification, a volume containing $2 \times 10^{7}$ lymphocyte cells was aliquoted into a 1.8 $\mathrm{ml}$ microfuge tube and centrifuged for $30 \mathrm{~s}$ using a dome microfuge. The supernatant fraction was removed and the lymphocyte cells were immediately frozen on dry ice prior to RNA extraction.

\section{RNA extraction}

The isolation of total RNA was adapted from the PureLink RNA mini kit (Life Technologies) protocol. A quantity of 1 $\mathrm{ml}$ of TRIzol reagent (Ambion) was added to $2 \times 10^{7}$ lymphocytes and vortexed and incubated at room temperature for 5 min. Following the 5-min incubation at room temperature, $0.2 \mathrm{ml}$ chloroform were added, the mixture was vigorously shaken and then centrifuged at $12000 \mathrm{~g}$ for $15 \mathrm{~min}$ at $4^{\circ} \mathrm{C}$. Following centrifugation, the aqueous layer was transferred to an RNase-free $1.8 \mathrm{ml}$ microfuge tube and an equal volume of $70 \%$ ethanol was added. After vigorous shaking, the solution was applied on the Spin Cartridge and centrifuged at $12000 \mathrm{~g}$ for $15 \mathrm{~s}$ at room temperature. Once the entire sample was loaded onto the column, $700 \mu$ l of Wash Buffer I were added and the mixture was centrifuged at $12000 \mathrm{~g}$ for $15 \mathrm{~s}$ at room temperature. The flow through was discarded and $500 \mu \mathrm{l}$ of Wash Buffer II were added, followed by another centrifugation step. The sample was centrifuged again to dry the membrane and $30 \mu \mathrm{l}$ of RNase-free water were added. Following a $1 \mathrm{~min}$ long incubation at room temperature, the column was centrifuged for $2 \mathrm{~min}$ and the RNA was transferred to an RNase-free microfuge tube. RNA quality was assessed using an Experion Automated Electrophoresis System (BioRad) and RNA with an RNA quality indicator (RQI) score greater than $9 \cdot 2$ was subsequently used for quantitative PCR analysis.

\section{TaqMan real-time RT-PCR}

The gene expression analysis method has been described previously in Berthelot et al. ${ }^{(36)}$. The High-Capacity cDNA Reverse Transcription kit from Applied Biosystems was used to synthesise first-strand cDNA from $168 \mathrm{ng}$ of total RNA. Baseline $(0 \mathrm{~h})$ and $6 \mathrm{~h}$ postprandial samples for both WC and WC+MFGM were analysed. Gene expression was quantified in triplicate using a ninety-six-well plate containing four endogenous control genes (actin, glyceraldehyde 3-phosphate dehydrogenase, hypoxanthine phosphoribosyltransferase 1 (HPRT1) and glucuronidase $\beta$ (GUSB)) as well as customdesigned TaqMan probes and primers. The probes and primers were designed to target ninety-two selected genes involved in inflammation and lipid metabolism. All gene amplification specificities, quality controls and reaction conditions were followed according to Applied Biosystems. Real-time PCR was performed using 50-fold diluted first-strand cDNA and the TaqMan Fast Advanced Master Mix on a Prism 7500 Fast real-time PCR thermocycler, under the following reaction conditions: $50^{\circ} \mathrm{C} / 2 \mathrm{~min} ; 95^{\circ} \mathrm{C} / 20 \mathrm{~s}$; and forty cycles of $95^{\circ} \mathrm{C} / 3 \mathrm{~s} ; 60^{\circ} \mathrm{C} / 30 \mathrm{~s}$.

Following amplification, expression levels of the target genes both in baseline samples and postprandial samples were 
calculated using the Pfaffl method ${ }^{(37)}$. This was done for each subject and normalised against HPRT1 and GUSB. Amplification efficiencies were analysed for each reaction using LinRegPCR software (Heart Failure Research Center version 2014.2; Academic Medical Center, Amsterdam, the Netherlands). $\Delta$ Cycle threshold $(\Delta \mathrm{Ct})$ values were corrected by their corresponding individual efficiencies.

\section{Statistical analysis}

Participant characteristics, baseline and postprandial markers and gene expression fold changes were all included in the statistical analyses. Sample size was determined using the means and standard deviations of the primary outcome marker, IL- $6{ }^{(38)}$. Postprandial time points were converted to a single iAUC value to quantify overall dietary response. Order by treatment effects were tested using two-way multivariate ANOVA on all response variables, with subject ID as a random variable. The residuals were then tested for normality using the Shapiro-Wilk test in JMP Pro 13. Normally distributed variables with no treatment by order effects were compared between treatments by testing the hypothesis that the within-subject difference across treatments was equal to zero (paired $t$ test). The Wilcoxon signed-rank test was used if the variables were non-normally distributed. Following the paired $t$ tests and signed-rank Wilcoxon test, BMI, sex, baseline SAA and baseline CRP were added as additional factors in an adjusted model along with subject and treatment. Secondary analysis using baseline cholesterol:HDL-cholesterol ratio (Chol:HDL) as a covariate was used to test for a treatment effect modification. For all genes with significant effect modification, correlation analyses were performed and $R^{2}$ values are reported. The Bonferroni correction was used to correct for the false discovery rate. Statistical significance was set to $P<0 \cdot 05$.

\section{Results}

\section{Participant characteristics}

A total of 207 participants were screened for the study, with thirty-eight completing enrolment and being randomised to order 1, in which the WC meal was given on the first test day, or order 2 , in which the WC+MFGM meal was given on the first test day. A total of thirty-six participants completed both test days and out of those thirty-six participants, an exploratory convenience subset of twenty was randomly selected for lymphocyte gene expression analysis. The results for the effects of the challenge meals on clinical and inflammatory markers are reported for all thirty-six subjects while the lymphocyte gene expression data are reported for the twentysubject subset. Approximately half from each order were analysed for lymphocyte gene expression.

Participant characteristics at baseline are shown in Table 2. The baseline parameters were averaged for each participant across the test days to determine order medians. Differences between baseline participant characteristics were not found between study days or between test meals.
Table 2. Participant baseline characteristics* and metabolic syndrome (MetS) criteria

(Mean values and standard deviations; numbers of participants)

\begin{tabular}{|c|c|c|c|}
\hline & Mean & SD & MetS criteria \\
\hline \multicolumn{4}{|l|}{ Participants $(n)$} \\
\hline Male & \multicolumn{2}{|c|}{17} & \\
\hline Female & \multicolumn{2}{|c|}{19} & \\
\hline Age (years) & $42 \cdot 9$ & 13.9 & \\
\hline $\mathrm{BMI}\left(\mathrm{kg} / \mathrm{m}^{2}\right)$ & $31 \cdot 7$ & $2 \cdot 6$ & \\
\hline Waist circumference (cm) & 99.7 & $7 \cdot 7$ & \\
\hline Waist circumference (males) (cm) & 103.9 & $1 \cdot 2$ & $>101 \cdot 6$ \\
\hline Waist circumference (females) (cm) & $95 \cdot 3$ & $1 \cdot 1$ & $>88.9$ \\
\hline Systolic blood pressure (mmHg) & $124 \cdot 1$ & $12 \cdot 9$ & $\geq 130$ \\
\hline Diastolic blood pressure (mmHg) & 72.4 & $10 \cdot 2$ & $\geq 85$ \\
\hline Chol:HDL† & 4.2 & $1 \cdot 1$ & \\
\hline TAG (mg/dl)‡ & $132 \cdot 6$ & $72 \cdot 6$ & $\geq 150$ \\
\hline Fasting glucose $(\mathrm{mg} / \mathrm{dl}) \ddagger$ & $89 \cdot 2$ & $13 \cdot 8$ & $\geq 100$ \\
\hline HDL-cholesterol (all subjects) (mg/dl) $\ddagger$ & $49 \cdot 0$ & 14.9 & \\
\hline HDL-cholesterol (males) (mg/dl)‡ & 43.1 & $2 \cdot 0$ & $<40$ \\
\hline HDL-cholesterol (females) (mg/dl)‡ & $56 \cdot 4$ & 2.8 & $<50$ \\
\hline $\operatorname{CRP}(\mu \mathrm{g} / \mathrm{l})$ & $4 \cdot 2$ & 4.6 & \\
\hline SAA $(\mu \mathrm{g} / \mathrm{l})$ & $7 \cdot 0$ & $23 \cdot 0$ & \\
\hline
\end{tabular}

Chol:HDL, cholesterol:HDL-cholesterol ratio; CRP, C-reactive protein; SAA, serum amyloid $A$.

* Each value represents a within-subject average from baseline on both study days. $\dagger$ Chol:HDL >4 represents significantly greater risk for CVD.

$\ddagger$ To convert TAG from $\mathrm{mg} / \mathrm{dl}$ to $\mathrm{mmol} / \mathrm{l}$, multiply by 0.01129 . To convert glucose from $\mathrm{mg} / \mathrm{dl}$ to $\mathrm{mmol} / \mathrm{l}$, multiply by 0.0555 . To convert $\mathrm{HDL}$-cholesterol from $\mathrm{mg} / \mathrm{dl}$ to $\mathrm{mmol} / \mathrm{l}$, multiply by 0.02586 .

\section{Test meal composition}

The greatest compositional differences between the WC and WC+MFGM meals were in median fatty acid content with total weight of SFA having a $0.93 \mathrm{~g}$ difference, PUFA a $0.47 \mathrm{~g}$ difference and MUFA a $0.18 \mathrm{~g}$ difference. Total PUFA content was significantly higher in the WC+MFGM meal. Linolenic acid was significantly lower in the WC+MFGM meal and arachidonic acid (ARA; $20: 4$ ) was significantly higher in the WC+MFGM meal. Palmitoleic acid (16:1) and linolenic acid $(18: 3)$ were significantly lower in the WC+MFGM meal. Butyric $(4: 0)$, caproic $(6: 0)$ and caprylic $(8: 0)$ acids were all significantly lower in the WC+MFGM meal.

\section{Lipid and metabolic parameters}

Hourly postprandial clinical data can be found in Tables 3 and 4 for the WC meal and the WC+MFGM meal, respectively.

The postprandial insulin iAUC was significantly lower after the WC+MFGM meal as compared with the WC meal $(P<$ 0.01) (Fig. 2). Median cortisol iAUC was found to decrease after both meals in the postprandial period, with a greater decrease following the meal with WC alone $(P=0.03)$.

Postprandial TAG, HDL-cholesterol, LDL-cholesterol, Chol:HDL and non-HDL-cholesterol were measured in the postprandial period; however, none was significantly different between test meals. At $3 \mathrm{~h}$ postprandially, mean TAG concentration was 248.1 (SD 138.4) mg/dl (2.8 (SD 1.6) mmol/l) after the WC meal and 243.3 (sD 104.4) $\mathrm{mg} / \mathrm{dl}(2 \cdot 8$ (sD 1.2) mmol/l) after the WC+MFGM meal. At $6 \mathrm{~h}$ postprandially, mean TAG concentration decreased to 203.0 (SD 110.5) $\mathrm{mg} / \mathrm{dl}(2.3$ (SD $1 \cdot 3$ ) $\mathrm{mmol} / \mathrm{l}$ ) after the WC meal and $206 \cdot 1$ (SD 107.0) $\mathrm{mg} / \mathrm{dl}$ $(2 \cdot 3$ (sD $1 \cdot 2) \mathrm{mmol} / \mathrm{l}$ ) after the WC+MFGM meal. 
Table 3. Hourly postprandial data for clinical and inflammatory markers following the whipping cream (WC) treatment (Mean values and standard deviations)

\begin{tabular}{|c|c|c|c|c|c|c|c|c|}
\hline \multirow[b]{2}{*}{ Variable } & \multicolumn{2}{|c|}{ Baseline } & \multicolumn{2}{|c|}{$1 \mathrm{~h}$} & \multicolumn{2}{|c|}{$3 \mathrm{~h}$} & \multicolumn{2}{|c|}{$6 \mathrm{~h}$} \\
\hline & Mean & SD & Mean & SD & Mean & SD & Mean & SD \\
\hline IL-10 (pg/ml) & 0.52 & 1.13 & 0.58 & 1.15 & 0.58 & 1.21 & 0.55 & 1.28 \\
\hline IL-1 $\beta(\mathrm{pg} / \mathrm{ml})$ & 0.09 & 0.18 & 0.09 & 0.17 & 0.08 & 0.15 & 0.09 & 0.18 \\
\hline IL-4 (pg/ml) & 0.06 & 0.05 & 0.07 & 0.05 & 0.06 & 0.05 & 0.05 & 0.05 \\
\hline IL-6 (pg/ml) & 0.70 & $1 \cdot 10$ & 0.63 & 1.18 & 0.60 & $1 \cdot 13$ & 0.87 & 1.51 \\
\hline IL-8 (pg/ml) & 11.05 & 3.44 & 10.98 & 3.03 & $10 \cdot 09$ & 2.69 & $10 \cdot 18$ & 3.06 \\
\hline TNF- $\alpha(\mathrm{pg} / \mathrm{ml})$ & 2.44 & 0.69 & $2 \cdot 38$ & 0.67 & $2 \cdot 27$ & 0.57 & $2 \cdot 32$ & 0.63 \\
\hline IL-18 (pg/ml) & $152 \cdot 27$ & 88.37 & $156 \cdot 90$ & $85 \cdot 32$ & $162 \cdot 02$ & $96 \cdot 78$ & $167 \cdot 18$ & $92 \cdot 36$ \\
\hline LBP $(\mu \mathrm{g} / \mathrm{ml})$ & 3.39 & 1.30 & 3.36 & 1.38 & 3.26 & 1.14 & 3.33 & $1 \cdot 21$ \\
\hline MCP-1 (pg/ml) & 354.88 & 93.35 & 358.99 & 82.68 & 347.65 & 88.75 & 326.69 & 101.09 \\
\hline CRP $(\mu \mathrm{g} / \mathrm{l})$ & 4.23 & 4.80 & 4.41 & 4.88 & 4.33 & 4.73 & 4.35 & 4.57 \\
\hline $\mathrm{SAA}(\mu \mathrm{g} / \mathrm{l})$ & 9.34 & $32 \cdot 20$ & 8.84 & 28.77 & 8.26 & $25 \cdot 75$ & 7.78 & 20.88 \\
\hline sICAM-1 ( $\mu \mathrm{g} / \mathrm{l})$ & 0.92 & 0.48 & 1.00 & 0.52 & 0.96 & 0.49 & 0.96 & 0.49 \\
\hline sVCAM-1 ( $\mu \mathrm{g} / \mathrm{l})$ & 1.49 & 0.83 & 1.58 & 0.90 & 1.50 & 0.84 & 1.53 & 0.86 \\
\hline Glucose $(\mathrm{mg} / \mathrm{dl})^{\star}$ & 90.47 & $10 \cdot 73$ & $80 \cdot 25$ & $19 \cdot 30$ & 87.44 & 11.79 & 85.81 & 5.80 \\
\hline Cholesterol (mg/dl)* & $202 \cdot 39$ & 43.47 & 204.61 & 39.57 & 203.42 & 41.00 & $206 \cdot 78$ & 39.94 \\
\hline HDL-cholesterol (mg/dl)* & 50.50 & 14.61 & $51 \cdot 14$ & 14.74 & 49.56 & 14.33 & $51 \cdot 22$ & 14.97 \\
\hline LDL-cholesterol (mg/dl) & $124 \cdot 31$ & 37.18 & 114.69 & 36.06 & 113.03 & 38.33 & $120 \cdot 69$ & 35.06 \\
\hline Chol:HDL ratio & 4.24 & 1.09 & 4.26 & 1.14 & 4.30 & 1.29 & 4.32 & $1 \cdot 23$ \\
\hline TAG $(\mathrm{mg} / \mathrm{dl})^{*}$ & $135 \cdot 08$ & 78.62 & 193.64 & 88.41 & 248.08 & 138.40 & 202.97 & 110.45 \\
\hline Non-HDL-cholesterol $(\mathrm{mg} / \mathrm{dl})^{*}$ & 151.89 & 40.09 & 153.47 & 37.23 & $153 \cdot 86$ & 39.62 & 155.56 & 38.31 \\
\hline Insulin $(\mu \mathrm{U} / \mathrm{ml})^{\star}$ & 15.59 & 11.09 & 84.72 & $68 \cdot 14$ & 39.94 & 35.82 & - & - \\
\hline
\end{tabular}

LBP, lipopolysaccharide binding protein; MCP-1, monocyte chemoattractant protein-1; CRP, C-reactive protein; SAA, serum amyloid A; sICAM-1, soluble intercellular adhesion molecule-1; sVCAM-1, soluble vascular cell adhesion molecule-1; Chol:HDL, cholesterol:HDL-cholesterol ratio.

* To convert glucose from $\mathrm{mg} / \mathrm{dl}$ to $\mathrm{mmol} / \mathrm{l}$, multiply by 0.0555 . To convert cholesterol from $\mathrm{mg} / \mathrm{dl}$ to $\mathrm{mmol} / \mathrm{l}$, multiply by 0.02586 . To convert TAG from mg/dl to mmol/l, multiply by 0.01129 . To convert insulin from $\mu \mathrm{U} / \mathrm{ml}$ to $\mathrm{pmol} / \mathrm{l}$, multiply by 6.945 .

The insulin iAUC response remained statistically significant after adjustment for BMI, sex, baseline SAA and baseline CRP $(P=0 \cdot 04)$.

\section{Inflammatory markers}

Hourly postprandial inflammatory markers data can be found in Tables 3 and 4 for the WC meal and the WC+MFGM meal, respectively.

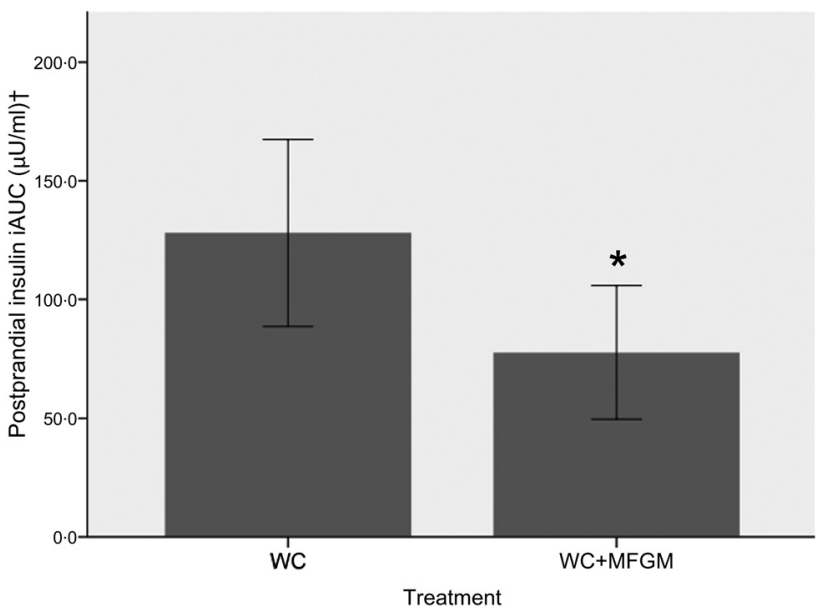

Fig. 2. Effect of milk fat globule membrane (MFGM) on insulin response following whipping cream (WC) and WC+MFGM meals. Values are means ( 36) of incremental AUC (iAUC) calculated from 1-3 h postprandially, with standard errors represented by vertical bars. * Mean value was significantly different from that for the WC treatment $(P<0.01 ; P<0.05$ adjusted). $†$ To convert insulin from $\mu \mathrm{U} / \mathrm{ml}$ to $\mathrm{pmol} / \mathrm{l}$, multiply by 6.945 .
IL-18 iAUC was significantly reduced following the WC + MFGM meal after adjustment $(P=0 \cdot 036$; Fig. 3(a)). IL-18 was found to reach a peak concentration of $167 \cdot 2$ (SD 92.4) $\mathrm{pg} / \mathrm{ml}$ at $6 \mathrm{~h}$ postprandially following the WC meal. After the WC+MFGM meal, IL-18 reached a peak concentration of $156 \cdot 1$ (SD 85.3$) \mathrm{pg} / \mathrm{ml}$ at $6 \mathrm{~h}$ postprandially; however, this value was nearly the same as the mean baseline concentration. Lipopolysaccharide (LPS) binding protein (LBP) iAUC (Fig. 3 (b)) was slightly higher following the WC+MFGM meal $(P=$ $0 \cdot 03$, adjusted), reaching its highest concentration of $3.8 \mu \mathrm{g} /$ $\mathrm{ml}$ at $6 \mathrm{~h}$ postprandially. Both IL-18 and LBP iAUC levels were not significant before adjusting for BMI, sex, baseline SAA and baseline CRP. IL-18 was not significant between test meals before adjustment $(P>0 \cdot 05)$, but was significant following adjustment $(P<0 \cdot 05)$. The outliers pictured are mild outliers and removing them did not change the statistical outcome of the test. The other cytokines and vascular adhesion molecules measured were not significantly different between test meals (IL-10, IL-1 $\beta$, IL-2, IL-4, IL-6, IL-8, TNF- $\alpha$, monocyte chemoattractant protein-1, CRP, SAA and soluble intercellular adhesion molecule).

\section{Lymphocyte gene expression}

The fold change in gene expression from baseline to $6 \mathrm{~h}$ following test meal consumption was measured. Fold change greater than 1.0 indicates increased gene expression, while fold change less than 1.0 indicates reduced gene expression from baseline. Fig. 4 shows that median soluble epoxide hydrolase (EPHX2) expression was significantly different following the WC+MFGM meal as compared with the WC meal 
Table 4. Hourly postprandial data for clinical and inflammatory markers following the whipping cream plus milk fat globule membrane (WC+MFGM) treatment

(Mean values and standard deviations)

\begin{tabular}{|c|c|c|c|c|c|c|c|c|}
\hline \multirow[b]{2}{*}{ Variable } & \multicolumn{2}{|c|}{ Baseline } & \multicolumn{2}{|c|}{$1 \mathrm{~h}$} & \multicolumn{2}{|c|}{$3 \mathrm{~h}$} & \multicolumn{2}{|c|}{$6 \mathrm{~h}$} \\
\hline & Mean & SD & Mean & SD & Mean & SD & Mean & SD \\
\hline IL-10 (pg/ml) & 0.52 & 1.08 & 0.57 & 1.09 & 0.57 & 1.04 & 0.58 & 1.17 \\
\hline IL-1 $\beta$ (pg/ml) & 0.08 & $0 \cdot 10$ & 0.08 & 0.11 & 0.07 & 0.09 & 0.08 & $0 \cdot 10$ \\
\hline IL-4 (pg/ml) & 0.07 & 0.05 & 0.06 & 0.05 & 0.07 & 0.06 & 0.06 & 0.06 \\
\hline IL-6 (pg/ml) & 0.78 & 1.43 & 0.63 & 1.27 & 0.60 & 1.20 & 0.86 & 1.48 \\
\hline IL-8 (pg/ml) & 11.79 & 3.64 & $10 \cdot 63$ & 4.11 & $10 \cdot 40$ & $3 \cdot 67$ & $10 \cdot 81$ & $3 \cdot 17$ \\
\hline TNF- $\alpha(p g / m l)$ & 2.54 & 0.83 & $2 \cdot 36$ & 0.81 & $2 \cdot 32$ & 0.81 & $2 \cdot 32$ & 0.73 \\
\hline IL-18 (pg/ml) & $154 \cdot 76$ & $80 \cdot 18$ & 154.41 & 78.68 & 151.73 & 84.08 & 156.08 & $85 \cdot 30$ \\
\hline LBP $(\mu \mathrm{g} / \mathrm{ml})$ & 3.32 & 1.24 & 3.44 & 1.26 & 3.39 & $1 \cdot 27$ & 3.51 & 1.60 \\
\hline MCP-1 (pg/ml) & 352.77 & 94.30 & 339.34 & 88.80 & 309.29 & $104 \cdot 27$ & 329.71 & $86 \cdot 41$ \\
\hline CRP $(\mu \mathrm{g} / \mathrm{l})$ & $4 \cdot 20$ & 4.43 & 4.39 & 4.64 & 4.42 & 4.79 & 4.51 & 4.82 \\
\hline SAA $(\mu \mathrm{g} / \mathrm{l})$ & 4.62 & $5 \cdot 34$ & 4.79 & 5.75 & 4.54 & $5 \cdot 36$ & $4 \cdot 81$ & $5 \cdot 37$ \\
\hline sICAM-1 ( $\mu \mathrm{g} / \mathrm{l})$ & 0.93 & 0.50 & 0.99 & 0.53 & 0.97 & 0.54 & 0.97 & 0.51 \\
\hline sVCAM-1 ( $\mu \mathrm{g} / \mathrm{l})$ & 1.49 & 0.85 & 1.56 & 0.90 & 1.51 & 0.87 & 1.56 & 0.88 \\
\hline Glucose $(\mathrm{mg} / \mathrm{dll})^{\star}$ & 87.88 & $16 \cdot 33$ & 75.06 & 21.84 & 88.83 & 9.83 & 88.33 & $7 \cdot 23$ \\
\hline Cholesterol $(\mathrm{mg} / \mathrm{dl})^{*}$ & 194.61 & 38.41 & $199 \cdot 36$ & 40.45 & 197.47 & $38 \cdot 60$ & 199.14 & $40 \cdot 00$ \\
\hline HDL-cholesterol (mg/dl)* & 47.56 & $15 \cdot 35$ & $50 \cdot 64$ & $16 \cdot 23$ & 49.14 & $15 \cdot 47$ & $50 \cdot 03$ & $15 \cdot 64$ \\
\hline LDL-cholesterol $(\mathrm{mg} / \mathrm{dl})^{*}$ & 118.42 & 34.77 & 111.81 & $35 \cdot 21$ & $100 \cdot 56$ & $35 \cdot 27$ & $109 \cdot 82$ & 35.97 \\
\hline Chol:HDL ratio & 4.19 & $1 \cdot 15$ & 4.23 & 1.17 & 4.32 & 1.23 & $4 \cdot 27$ & 1.17 \\
\hline TAG $(\mathrm{mg} / \mathrm{dl})^{\star}$ & 130.05 & 67.06 & 184.44 & 78.01 & $243 \cdot 31$ & $104 \cdot 38$ & 206.06 & $106 \cdot 93$ \\
\hline Non-HDL-cholesterol (mg/dl)* & 144.72 & 34.52 & 148.72 & 35.91 & $148 \cdot 33$ & 35.48 & 149.08 & 37.05 \\
\hline Insulin $(\mu \mathrm{U} / \mathrm{ml})^{\star}$ & 14.38 & $8 \cdot 11$ & 52.03 & 54.43 & 35.63 & 24.35 & - & - \\
\hline
\end{tabular}

LBP, lipopolysaccharide binding protein; MCP-1, monocyte chemoattractant protein-1; CRP, C-reactive protein; SAA, serum amyloid A; sICAM-1, soluble intercellular adhesion molecule-1; sVCAM-1, soluble vascular cell adhesion molecule-1; Chol:HDL, cholesterol:HDL-cholesterol ratio.

* To convert glucose from $\mathrm{mg} / \mathrm{dl}$ to $\mathrm{mmol} / \mathrm{l}$, multiply by 0.0555 . To convert cholesterol from $\mathrm{mg} / \mathrm{dl}$ to $\mathrm{mmol} / \mathrm{l}$, multiply by 0.02586 . To convert TAG from $\mathrm{mg} / \mathrm{dl}$ to $\mathrm{mmol} / \mathrm{l}$, multiply by 0.01129 . To convert insulin from $\mu \mathrm{U} / \mathrm{ml}$ to $\mathrm{pmol} / \mathrm{l}$, multiply by 6.945 .

$(P=0.009, \quad P=0.02$ after adjustment). The median fold change following the WC meal was $1 \cdot 23$, indicating up-regulation from baseline. Responses across the interquartile range varied from no difference in EPHX2 expression at $6 \mathrm{~h}$ postprandially, to almost 2 -fold higher expression at $6 \mathrm{~h}$. After the WC+MFGM meal, the median fold change was approximately 1.0 , with participants varying from no change in expression at $6 \mathrm{~h}$, to only 1.3-fold higher expression at 6 h. These fold changes are shown in Table 5 . There was a significant treatment by order effect for iAUC percentage eosinophils $(P=0.03)$, and a significant order effect for the iAUC fold change of CYP4A11 $(P=0 \cdot 03)$.

Effect of baseline markers on gene expression following milk fat globule membrane treatment

Lymphocyte gene expression following MFGM treatment showed significant differences based on baseline Chol:HDL. The fold changes of the following genes were significantly different when considering the interaction between baseline Chol: HDL and treatment: cluster of differentiation 14 (CD14), lymphotoxin $\beta$ receptor (LTBR), BTRC, IRAK1, TLR7, TNFRSF10B, TBXAS1, BCL2, NFKB2, REL, TRAF4, EPHX1, IKBKG, NFKBIE, EPHX2, TRAF1, TLR2, TRAF5, IRAK1BP1, PTAFR, BCL3, IL1B, TNFRSF1A, TLR4, CSF1 and PLA2G7 (Table 5). Following Bonferroni correction, only differences in CD14 and LTBR expression remained significant. The relationship between Chol:HDL, treatment, and both CD14 and LTBR fold changes are shown in Fig. 5. Individuals with a higher Chol:HDL at baseline were more likely to show decreased CD14 expression with the addition of MFGM. In the absence of MFGM, individuals with higher baseline Chol:HDL were more likely to show no change or slightly increased CD14 expression. For LTBR, the addition of MFGM also had a stronger effect on individuals with a higher baseline Chol:HDL.

\section{Discussion}

The addition of MFGM to a high-SFA dairy product-based meal resulted in a significant decrease in insulin response and attenuation of lymphocyte soluble epoxide hydrolase $(\mathrm{sEH})$ expression. Secondary analyses showed that the effect of MFGM on the expression of CD14 and LTBR is modified by fasting baseline Chol:HDL. These findings suggest that adding MFGM to a meal high in dairy fat beneficially decreases postprandial insulinaemia and $\mathrm{sEH}$ induction in overweight and obese individuals, and would be particularly beneficial for those individuals with a high Chol:HDL.

Native MFGM consists of a phospholipid trilayer which arises from the endoplasmic reticulum and plasma membrane in the mammary epithelial cell. The structure allows for the TAG-rich fraction of milk to be separated from the water-soluble fraction ${ }^{(39)}$. MFGM carries a wide array of lipids and proteins, including phospholipids, glycolipids and sphingolipids. These components are not only important to the bactericidal properties of MFGM through their ability to form lipid rafts, but also deliver these lipids for distribution in cells of the body ${ }^{(23,39)}$. Milk products that have undergone various levels of processing and homogenisation retain 

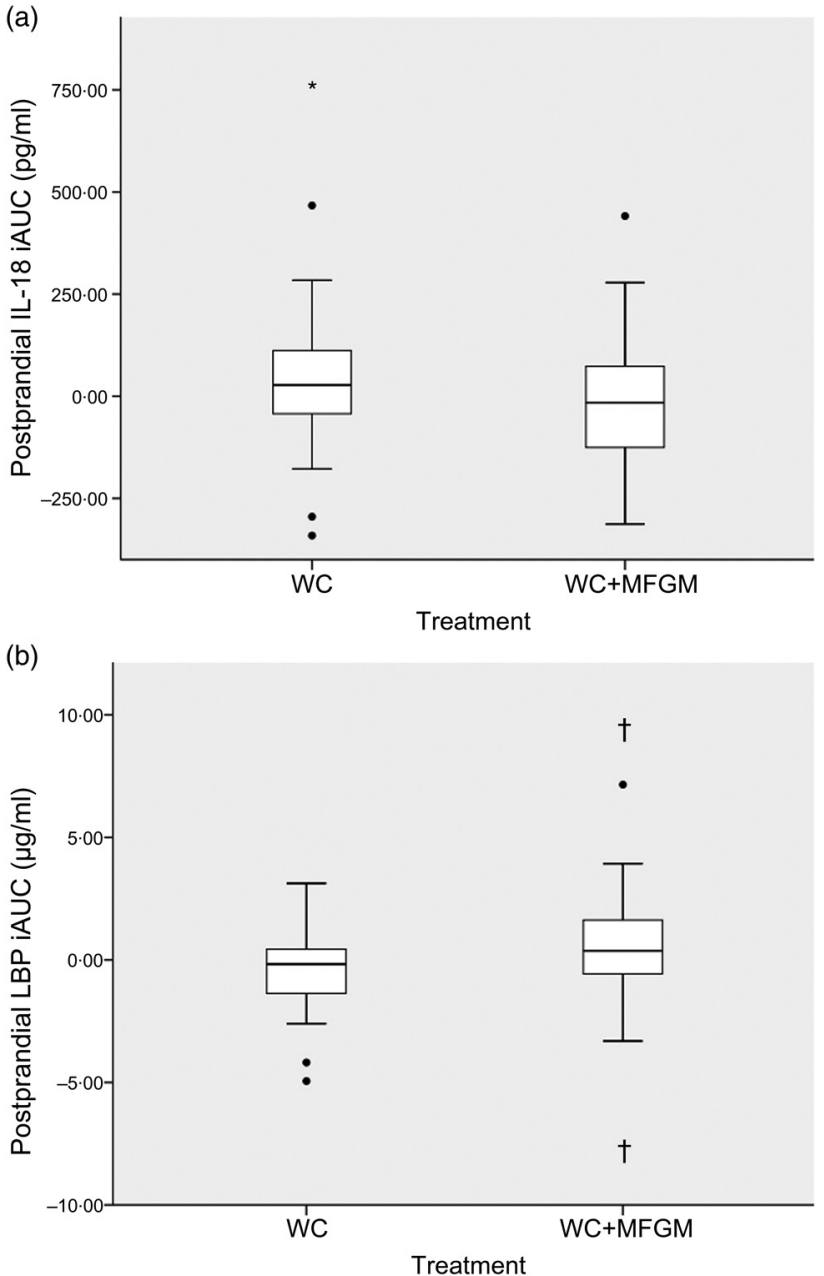

Fig. 3. (a) Effect of milk fat globule membrane (MFGM) on IL-8 (a) and lipopolysaccharide binding protein (LBP) (b) responses following whipping cream (WC) and WC+MFGM meals. Values are medians $(n 36)$ of incremental AUC (iAUC) calculated from 1,3 and $6 \mathrm{~h}$ postprandially, with ranges represented by vertical bars. * Median value was different from that for the WC treatment $(P>0.05$ unadjusted; $P<0.05$ adjusted). $t$ Median value was significantly different from that for the WC treatment $(P<0.05$ unadjusted; $P<0.005$ adjusted). $\bullet$, Outliers.

some of the components of MFGM but not in the native structure $^{(22)}$. This study was not designed to test which specific components are directly responsible for the observed effects.

Postprandial insulin was found to be significantly reduced following consumption of MFGM. This response was significant when looking at all participants regardless of baseline characteristics or MetS traits. This insulin response was consistent with another experiment in the same subject population testing the effects of adding MFGM to a meal high in palm oil $^{(13)}$. This previous study by Demmer et al. ${ }^{(13)}$ showed that addition of MFGM to palm oil significantly reduces insulin by $50 \%$, with a corresponding decrease in postprandial glucose concentration, a significant increase in TAG, and a decrease in LDL-cholesterol. The present study found no difference in postprandial glucose concentration between WC and WC+MFGM test meals, suggesting that for glucose, the effect of MFGM may depend on whether it is consumed with dairy or palm oil, whereas a similar effect was seen for

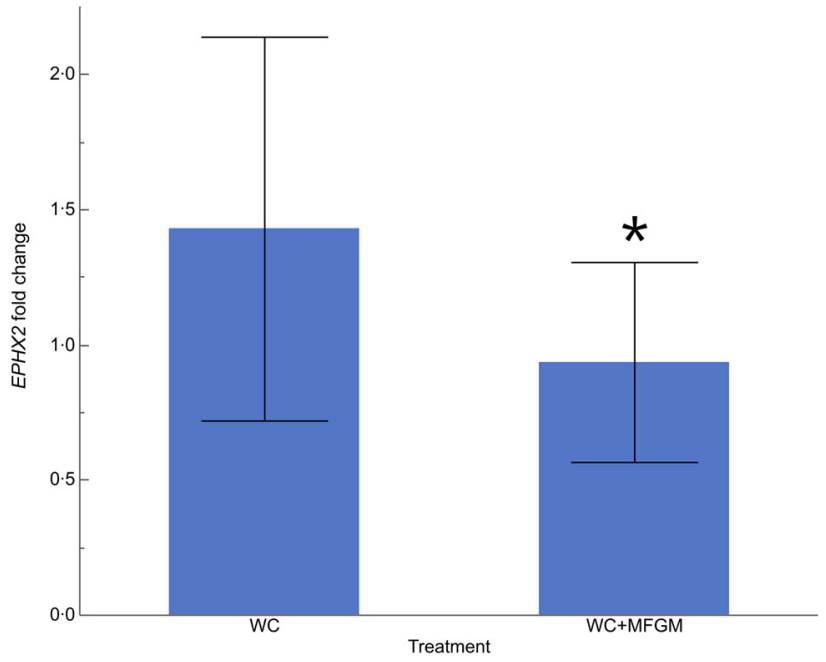

Fig. 4. Effect of milk fat globule membrane (MFGM) on fold change of soluble epoxide hydrolase gene (EPHX2) in lymphocytes, from baseline to $6 \mathrm{~h}$ postprandially. Values are means ( $n 20$ ) of incremental AUC (iAUC), with standard errors represented by vertical bars. ${ }^{*}$ Mean value was significantly different from that for the whipping cream (WC) treatment $(P<0.01 ; P<0.05$ after adjustment).

insulin and TAG response despite the source of the saturated fat. Additionally, the study by Demmer et al. ${ }^{(13)}$ demonstrated a significant effect modification of baseline CRP concentration on postprandial IL-6 response following the palm oil meal. Therefore, the present analysis included baseline CRP in the adjusted model.

Neither changes to cholesterol levels nor TAG were apparent within the $6 \mathrm{~h}$ postprandial collection window in the present study. A study by Irawati et al. ${ }^{(14)}$ investigated the postprandial response of healthy normal subjects following a high-fat meal (40 $\mathrm{g}$ fat from a mixed meal containing either palm oil, coconut oil or rice bran oil). They found that across all treatments ten out of twenty-six participants show $4 \mathrm{~h}$ postprandial TAG levels greater than $1.7 \mathrm{mmol} / 1$ (approximately $150 \mathrm{mg} / \mathrm{dl}$ ). These TAG levels are not related to fasting cholesterol levels or even fasting TAG. The results from Irawati et al. ${ }^{(14)}$ suggest that fasting lipids may not be an appropriate indicator of how the body handles postprandial TAG. Another study by Schmid et al. ${ }^{(21)}$ looked at blood lipids following high-fat meals either with or without dairy products. They fed healthy men a meal in which $60 \%$ of the energy came from fat. At $4 \mathrm{~h}$ postprandially, they found TAG iAUC significantly increased following the high-fat dairy product meal. They also found that the meal containing dairy fat resulted in no significant increases in the inflammatory cytokines IL-6, TNF- $\alpha$ and CRP, compared with the meals without dairy fat ${ }^{(21)}$. This suggests that dairy product-derived fat is not more inflammatory than palm oil-derived saturated fat. The increased TAG levels following the WC+MFGM meal in this study may be related to the significantly lower magnitude of the postprandial insulin rise that was also observed after the WC+MFGM meal. Insulin is a hormonal regulator of lipoprotein lipase, which converts TAG into glycerol and NEFA that diffuse into the adipose tissue before being reassembled into TAG for storage ${ }^{(40)}$. A lower rise in insulin 
Table 5. Fold changes in lymphocyte gene expression following whipping cream (WC) and WC + milk fat globule membrane (MFGM) treatments $\uparrow$ (Mean values, standard deviations and $95 \%$ confidence intervals; coefficients of determination $\left(R^{2}\right)$ )

\begin{tabular}{|c|c|c|c|c|c|c|c|c|c|}
\hline \multirow[b]{2}{*}{ Gene } & \multicolumn{4}{|c|}{ WC } & \multicolumn{4}{|c|}{ WC+MFGM } & \multirow[b]{2}{*}{ Baseline Chol:HDL $\times$ treatmen } \\
\hline & Mean & SD & $95 \% \mathrm{Cl}$ & $R^{2}$ & Mean & SD & $95 \% \mathrm{Cl}$ & $R^{2}$ & \\
\hline$C D 14$ & 1.02 & 0.36 & 0.17 & 0.14 & 1.07 & 0.49 & 0.23 & 0.46 & $<0.001^{*}$ \\
\hline$L T B R$ & 1.01 & 0.43 & 0.20 & 0.15 & 1.08 & 0.55 & 0.26 & 0.29 & $<0.001^{*}$ \\
\hline$B T R C$ & $1 \cdot 16$ & 0.44 & 0.21 & 0.24 & $1 \cdot 16$ & 0.35 & $0 \cdot 16$ & 0.28 & $<0.001$ \\
\hline IRAK1 & 1.07 & 0.26 & 0.12 & 0.02 & 1.02 & 0.35 & $0 \cdot 16$ & 0.51 & $<0.01$ \\
\hline TLR7 & 1.32 & 0.54 & 0.25 & 0.13 & 1.34 & 0.44 & 0.21 & 0.27 & $<0.01$ \\
\hline TNFRSF10B & 0.95 & 0.33 & 0.15 & 0.07 & 1.07 & 0.46 & 0.21 & 0.47 & $<0.01$ \\
\hline TBXAS1 & 0.90 & 0.43 & 0.20 & 0.22 & 1.11 & 0.51 & 0.24 & 0.25 & $<0.01$ \\
\hline BCL2 & 0.93 & 0.33 & 0.15 & 0.08 & 1.07 & 0.48 & 0.22 & 0.20 & $<0.01$ \\
\hline NFKB2 & 1.29 & 0.69 & 0.32 & 0.29 & 1.27 & 0.51 & 0.24 & 0.17 & $<0.01$ \\
\hline$R E L$ & 1.28 & 0.46 & 0.21 & 0.04 & 1.29 & 0.65 & 0.30 & 0.26 & $<0.01$ \\
\hline TRAF4 & 1.05 & 0.44 & 0.21 & 0.04 & 1.09 & 0.31 & 0.14 & 0.17 & $<0.01$ \\
\hline$E P H X 1$ & 1.21 & 0.45 & 0.21 & 0.06 & 1.22 & 0.59 & 0.28 & 0.38 & $<0.01$ \\
\hline IKBKG & $1 \cdot 14$ & 0.46 & 0.21 & 0.09 & 1.02 & 0.45 & 0.21 & 0.25 & $<0.01$ \\
\hline NFKBIE & $1 \cdot 15$ & 0.48 & 0.22 & 0.05 & 1.07 & 0.43 & 0.20 & 0.16 & 0.01 \\
\hline$E P H X 2$ & 1.43 & 0.71 & 0.33 & 0.23 & 0.94 & 0.37 & 0.17 & 0.09 & 0.01 \\
\hline TRAF1 & 1.27 & 0.65 & 0.30 & 0.19 & $1 \cdot 12$ & 0.30 & 0.14 & 0.18 & 0.02 \\
\hline TLR2 & 0.97 & 0.27 & 0.12 & 0.14 & $1 \cdot 10$ & 0.46 & 0.22 & 0.13 & 0.02 \\
\hline TRAF5 & 1.22 & 0.49 & 0.23 & 0.09 & 1.27 & 0.51 & 0.24 & 0.20 & 0.02 \\
\hline IRAK1BP1 & 1.37 & 0.69 & 0.32 & 0.34 & 1.41 & 0.63 & 0.29 & 0.06 & 0.02 \\
\hline PTAFR & 1.04 & 0.29 & 0.14 & 0.00 & 0.92 & 0.34 & $0 \cdot 16$ & 0.23 & 0.03 \\
\hline BCL3 & 1.22 & 0.48 & 0.22 & 0.10 & 1.02 & 0.36 & 0.17 & $0 \cdot 10$ & 0.03 \\
\hline IL1B & 1.06 & 0.44 & 0.21 & 0.16 & 1.17 & 0.67 & 0.31 & 0.04 & 0.03 \\
\hline TNFRSF1A & 1.13 & 0.49 & 0.23 & 0.10 & 1.05 & 0.36 & 0.17 & 0.18 & 0.04 \\
\hline TLR4 & 1.07 & 0.49 & 0.23 & 0.13 & 1.02 & 0.49 & 0.23 & 0.13 & 0.04 \\
\hline CSF1 & 1.39 & 0.71 & 0.33 & 0.05 & 1.46 & 0.69 & 0.32 & 0.26 & 0.04 \\
\hline PLA2G7 & 0.94 & 0.37 & 0.17 & 0.08 & 1.12 & 0.60 & 0.28 & 0.11 & 0.04 \\
\hline
\end{tabular}

Chol:HDL, cholesterol:HDL-cholesterol ratio; $C D 14$, cluster of differentiation 14; $L T B R$, lymphotoxin $\beta$ receptor; $B T R C, \beta$-transducin repeat containing $\mathrm{E} 3$ ubiquitin protein ligase; IRAK1, IL-1 receptor associated kinase 1; TLR7, toll-like receptor 7; TNFRSF10B, TNF receptor superfamily member 10b; TBXAS1, thromboxane A synthase 1; NFKB2, NF-KB subunit 2; TRAF4, TNF receptor associated factor 4; EPHX1, epoxide hydrolase 1; IKBKG, inhibitor of NF-kB kinase subunit $\gamma$; NFKBIE, NFKB inhibitor $\varepsilon$; EPHX2, soluble epoxide hydrolase; TRAF1, TNF receptor associated factor 1; TLR2, toll-like receptor 2; TRAF5, TNF receptor associated factor 5; IRAK1BP1, IL-1 receptor associated kinase 1 binding protein 1; PTAFR, platelet activating factor receptor; TNFRSF1A, TNF receptor superfamily member 1a; TLR4, toll-like receptor 4; CSF1, colony stimulating factor 1 ; PLA2G7, phospholipase A2 group VII.

${ }^{\star}$ Significant after Bonferroni correction $(P<0.05)$.

$\dagger$ Fold changes after testing for an effect modification of baseline Chol:HDL on treatment. All genes listed were significant for the effect modification.

would suggest lowered lipoprotein lipase activity, allowing more TAG to remain in the plasma. However, to fully appreciate the contributing factors to the observed TAG results, hepatic uptake and release should also be assessed. Another possibility is that peripheral glucose uptake is favoured in the postprandial state following MFGM treatment. After the WC+MFGM meal, mean $1 \mathrm{~h}$ plasma glucose was $75.1 \mathrm{mg} /$ dl $(4.2 \mathrm{mmol} / \mathrm{l})$, slightly lower than the $80.3 \mathrm{mg} / \mathrm{dl}(4.5$ $\mathrm{mmol} / \mathrm{l}$ ) plasma glucose following WC alone, but not statistically significant. Future studies should examine these possibilities to determine whether the overall net effect of MFGM is beneficial on postprandial glucose metabolism and lipaemia.

IL-18 was found to decrease and LBP to increase following the addition of MFGM; however, these differences did not reach significance until after adjusting for BMI, sex, baseline SAA and baseline CRP. IL-18 is a pro-inflammatory cytokine linked to CVD risk and is related to the production of other pro-inflammatory cytokines such as TNF- $\alpha$ and IL-1 $\beta^{(13)}$. Esposito et al. ${ }^{(41)}$ have shown that IL-18 increases following acute hyperglycaemia. Increased IL-18 can stimulate macrophage differentiation and may induce expression of adhesion molecules $^{(41)}$. Future studies should address whether MFGM reduces IL-18 expression in order to determine if MFGM is beneficial in the postprandial state.
LBP binds free plasma LPS and can stimulate macrophages to produce soluble CD14, which then can facilitate transfer of LPS to HDL, allowing clearance through reverse cholesterol transport activity ${ }^{(42)}$. A study by Laugerette et al. ${ }^{(43)}$ found that in healthy males, chronic overfeeding results in a higher plasma LBP level after the intervention. It was also noted that participants with a higher fasting LBP level before the study intervention had a higher LBP:soluble CD14 ratio at the end of the study ${ }^{(43)}$. LBP had the highest range of responses at $6 \mathrm{~h}$ postprandially, with responses from 1.4 to $9.3 \mu \mathrm{g} / \mathrm{ml}$. These findings underscore the importance of studying the interindividual variability in inflammatory response following different meals and suggest that some individuals are particularly susceptible to the pro-inflammatory effects of certain types of meals.

Lymphocyte expression of EPHX2 was attenuated with addition of MFGM. EPHX2 encodes sEH, an enzyme expressed in many tissues including the heart, kidneys, liver and vascular endothelium ${ }^{(44)}$. sEH converts the epoxyeicosatrienoic acids formed from cytochrome P450 metabolism of fatty acids such as ARA, DHA, $\alpha$-linolenic acid (ALA) and linoleic acid (LA) into their corresponding diols such as dihydroxyeicosatrienoic acids ${ }^{(45)}$. Whereas this conversion allows for increased solubility, lower bioactivity and better excretion 

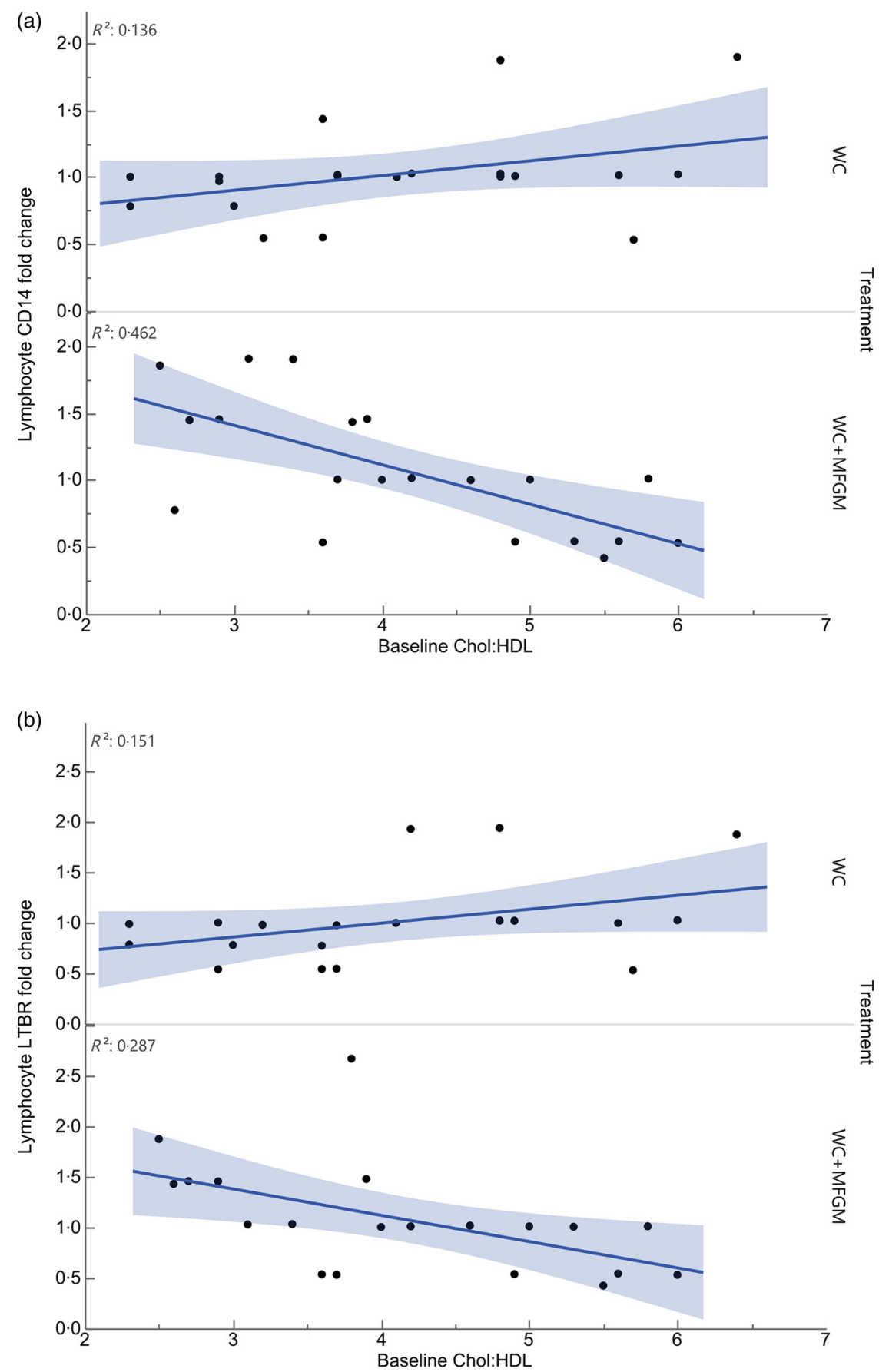

Fig. 5. Effect modification of baseline cholesterol:HDL-cholesterol (Chol:HDL) on (a) lymphocyte cluster of differentiation 14 (CD14) and (b) lymphotoxin $\beta$ receptor $(L T B R)$ gene expression fold changes from baseline to $6 \mathrm{~h}$ postprandially $(n 20)(P<0.001)$. WC, whipping cream; WC+MFGM, whipping cream + milk fat globule membrane.

of the epoxyeicosatrienoic acid products of ARA, the dihydroxyeicosatrienoic acids have been shown to have proinflammatory activity ${ }^{(45,46)}$. In the absence of sEH, epoxyeicosatrienoic acids exert their effects for a longer period of time. The epoxides and diols produced from different precursor fatty acids (DHA, ALA, LA, etc.) have slightly different biological activities compared with the ARA-derived metabolites ${ }^{(45)}$. Epoxyeicosatrienoic acids produced from ARA are resolvers of inflammation, play a role in lowering pain and blood pressure, and can influence the production of and tissue responsiveness to insulin ${ }^{(47)}$. Although the present study found no difference in glucose levels, insulin levels were significantly reduced with the MFGM meal. Although the link between MFGM, sEH and insulin metabolism is not yet known, the present study provides additional evidence of an effect of MFGM on insulin signalling pathways as well as pathways involved in the resolution of inflammation.

Baseline Chol:HDL was analysed to test for an effect modification on treatment. Chol:HDL has been reported to be a predictor of not only CVD, but T2DM as well ${ }^{(48,49)}$. Several large prospective studies have shown that the higher the Chol:HDL, the more likely individuals will experience a 
CVD event, with a ratio of 5.5 presenting moderate atherogenic risk ${ }^{(48)}$.

All genes that were affected by baseline Chol:HDL under the MFGM treatment showed either a decrease or an attenuation of fold change from baseline to $6 \mathrm{~h}$ postprandially as the baseline Chol:HDL increased, suggesting that MFGM may be particularly beneficial in individuals with high-risk lipoprotein profiles (Table 5). After correcting for the false discovery rate, only CD14 and LTBR remained significant. Lymphocyte CD14 fold change showed a slight elevation under the WC meal alone with increasing baseline Chol: HDL. Upon addition of MFGM, the participants with higher baseline Chol:HDL had the greatest reductions in lymphocyte CD14 gene expression. Under the MFGM test meal, five out of seven participants with reductions in CD14 gene expression had baseline Chol:HDL ratios greater than 4.5 . The same trend was seen for LTBR, in that the participants with the highest Chol:HDL ratios at baseline experienced the most significant reduction in LTBR fold change. When these high Chol:HDL ratio participants were given the WC meal, they generally had LTBR fold change increases. This suggests that MFGM plays a protective role for those individuals at a higher atherogenic risk based on Chol:HDL. One role of CD14 is to facilitate the removal of LPS from plasma ${ }^{(50)}$. Baseline Chol: HDL had no effect modification on plasma LBP response $(P=0.73)$ directly; however, addition of MFGM to the highfat meal increased postprandial LBP. Both CD14 and LBP can carry or exchange LPS in the plasma. Converting the plasma LBP response into a baseline to $6 \mathrm{~h}$ fold change showed slight increases from baseline following both meals, whereas lymphocyte CD14 fold changes were smaller following the WC+MFGM meal. LTBR is primarily expressed on the vascular endothelium and hepatocytes; however, it is also expressed on monocytes ${ }^{(51)}$. LTBR binds lymphotoxin ligands on lymphocytes and is involved in inflammatory signal transduction pathways as part of the TNF family of receptors ${ }^{(51)}$. Although the role of LTBR in CVD is not completely clear, recent literature suggests that it is associated with the promotion of atherosclerosis ${ }^{(51,52)}$. Therefore, the results from the present study indicate a protective role of adding MFGM to dairy fat for those individuals with higher baseline Chol:HDL.

The present study was designed to test the effects of adding MFGM to a high-fat meal to understand whether adding back complex lipid and protein components that would normally be present in unpasteurised, unhomogenised milk would attenuate postprandial inflammation. This study provides several investigative directions for future postprandial studies. The MetS population is highly varied, with different symptoms resulting from different underlying metabolic processes. It will therefore be necessary to study clinically similar cohorts to come up with specific MFGM recommendations in future studies.

\section{Conclusion}

The present study shows that addition of MFGM to a meal high in saturated fat can have significant effects on postprandial inflammation and metabolism. The results here warrant future research on how MFGM as a dietary additive can be beneficial to those individuals whose lifestyle, diet and genetics predisposes them to chronic inflammation, insulin resistance and CVD. Treatment strategies encompassing diet, medication, lifestyle changes and incorporation of nutraceuticals like MFGM may accelerate the redevelopment of healthy metabolic profiles in these individuals.

\section{Acknowledgements}

The authors would like to thank the study participants for their time and efforts to comply with the study requirements. The authors thank Fonterra Co-operative Group Ltd (New Zealand) for supplying the BCP50 product for use in this study. The authors thank the Western Human Nutrition Research Center kitchen personnel, Dustin Burnett, Sara Dowling and Julie Edwards; phlebotomist, Jerome Crawford; physiologist, Mary Gustafson; and molecular biologist, Pieter Oort for their dedication to the project. Special thanks are also given to Rebecca Young for her guidance on the statistical analyses. The US Department of Agriculture is an equal opportunity employer and provider.

This work was supported by the National Dairy Council (M. D. V. L., A. M. Z. and J. T. S.) and the US Department of Agriculture, Agricultural Research Service, Western Human Nutrition Research Center, Jastro Shields Fellowship.

A. M. Z., J. T. S., J. B. G. and M. D. V. L. designed the research; E. D., N. R., T. S. R.-S. and E. R. G. conducted the research; E. B. analysed the data; and E. B. and A. M. Z. wrote the paper. E. B. had primary responsibility for the final content. All authors read and approved the final manuscript.

M. D. V. L., A. M. Z. and J. T. S. have received research funding from the National Dairy Council; A. M. Z. received a stipend from the National Dairy Council to present a talk at a symposium in 2013. The founding sponsors had no role in the design of the study; in the collection, analyses or interpretation of the data; in the writing of the manuscript, and in the decision to publish the results.

\section{References}

1. Astrup A, Dyerberg J, Elwood P, et al. (2011) The role of reducing intakes of saturated fat in the prevention of cardiovascular disease: where does the evidence stand in 2010? Am J Clin Nutr 93, 684688.

2. Howard BV, Van Horn L, Hsia J, et al. (2006) Low-fat dietary pattern and risk of cardiovascular disease: the Women's Health Initiative Randomized Controlled Dietary Modification Trial. JAMA 295, 655-666.

3. Margioris AN (2009) Fatty acids and postprandial inflammation. Curr Opin Clin Nutr Metab Care 12, 129-137.

4. Harford KA, Reynolds CM, McGillicuddy FC, et al. (2011) Fats, inflammation and insulin resistance: insights to the role of macrophage and T-cell accumulation in adipose tissue. Proc Nutr Soc 70, 408-417.

5. Teng K-T, Chang C-Y, Chang L, et al. (2014) Modulation of obesity-induced inflammation by dietary fats: mechanisms and clinical evidence. Nutr J 13, 12.

6. Weisberg SP, McCann D, Desai M, et al. (2003) Obesity is associated with macrophage accumulation in adipose tissue. J Clin Invest 112, 1796-1808. 
7. Monteiro R \& Azevedo I (2010) Chronic inflammation in obesity and the metabolic syndrome. Mediators Inflamm 2010, 289645.

8. Aguilar M, Bhuket T, Torres S, et al. (2015) Prevalence of the metabolic syndrome in the United States, 2003-2012. JAMA 313, 19731974.

9. Yusof NM, Rahman JA, Zulkifly AH, et al. (2015) Predictors of major lower limb amputation among type II diabetic patients admitted for diabetic foot problems. Singapore Med J 56, 626-631.

10. Hippisley-Cox J \& Coupland C (2016) Diabetes treatments and risk of amputation, blindness, severe kidney failure, hyperglycaemia, and hypoglycaemia: open cohort study in primary care. Br Med J 352, i1450.

11. Srikanthan K, Feyh A, Visweshwar H, et al. (2016) Systematic review of metabolic syndrome biomarkers: a panel for early detection, management, and risk stratification in the West Virginian population. Int J Med Sci 13, 25-38.

12. Shin J-A, Lee J-H, Lim S-Y, et al. (2013) Metabolic syndrome as a predictor of type 2 diabetes, and its clinical interpretations and usefulness. J Diabetes Investig 4, 334-343.

13. Demmer E, Van Loan MD, Rivera N, et al. (2016) Addition of a dairy fraction rich in milk fat globule membrane to a high-saturated fat meal reduces the postprandial insulinaemic and inflammatory response in overweight and obese adults. J Nutr S $c i$ 5, e14.

14. Irawati D, Mamo JCL, Slivkoff-Clark KM, et al. (2017) Dietary fat and physiological determinants of plasma chylomicron remnant homoeostasis in normolipidaemic subjects: insight into atherogenic risk. Br J Nutr 117, 403-412.

15. Nakamura K, Miyoshi T, Yunoki K, et al. (2016) Postprandial hyperlipidemia as a potential residual risk factor. J Cardiol 67, 335-339.

16. Higgins V \& Adeli K (2017) Postprandial dyslipidemia: pathophysiology and cardiovascular disease risk assessment. EJIFCC 28, 168184.

17. Astrup A (2014) Yogurt and dairy product consumption to prevent cardiometabolic diseases: epidemiologic and experimental studies. Am J Clin Nutr 99, 1235S-1242S.

18. Drouin-Chartier J-P, Brassard D, Tessier-Grenier M, et al. (2016) Systematic review of the association between dairy product consumption and risk of cardiovascular-related clinical outcomes. Adv Nutr 7, 1026-1040.

19. Thorning TK, Raben A, Tholstrup T, et al. (2016) Milk and dairy products: good or bad for human health? An assessment of the totality of scientific evidence. Food Nutr Res 60, 32527.

20. Rosqvist F, Smedman A, Lindmark-Månsson H, et al. (2015) Potential role of milk fat globule membrane in modulating plasma lipoproteins, gene expression, and cholesterol metabolism in humans: a randomized study. Am J Clin Nutr 102, 20-30.

21. Schmid A, Petry N, Walther B, et al. (2015) Inflammatory and metabolic responses to high-fat meals with and without dairy products in men. Br J Nutr 113, 1853-1861.

22. Argov N, Lemay DG \& German JB (2008) Milk fat globule structure and function: nanoscience comes to milk production. Trends Food Sci Technol 19, 617-623.

23. Martini M, Salari F \& Altomonte I (2016) The macrostructure of milk lipids: the fat globules. Crit Rev Food Sci Nutr 56, 1209-1221.

24. Idei M, Hirayama S, Miyake N, et al. (2014) Mean postprandial triglyceride concentration is an independent risk factor for carotid atherosclerosis in patients with type 2 diabetes. Clin Chim Acta 430, 134-139.

25. Luque-Ramírez M, Martínez-García MÁ, Montes-Nieto $\mathrm{R}$, et al. (2013) Sexual dimorphism in adipose tissue function as evidenced by circulating adipokine concentrations in the fasting state and after an oral glucose challenge. Hum Reprod 28, 1908-1918.

26. Westerink J, Hajer GR, Kranendonk MEG, et al. (2014) An oral mixed fat load is followed by a modest anti-inflammatory adipocytokine response in overweight patients with metabolic syndrome. Lipids 49, 247-254.

27. Yacoub M, Hassan M, Latif N, et al. (2012) Adipose tissue: friend or foe? Nat Rev Cardiol 9, 689-702.
28. Stalenhoef AF \& de Graaf J (2008) Association of fasting and nonfasting serum triglycerides with cardiovascular disease and the role of remnant-like lipoproteins and small dense LDL. Curr Opin Lipidol 19, 355-361.

29. Zilversmit DB (1995) Atherogenic nature of triglycerides, postprandial lipidemia, and triglyceride-rich remnant lipoproteins. Clin Chem 41, 153-158.

30. Grundy SM, Cleeman JI, Daniels SR, et al. (2005) Diagnosis and management of the metabolic syndrome: an American Heart Association/National Heart, Lung, and Blood Institute Scientific Statement. Circulation 112, 2735-2752.

31. Pedersen A, Sandström B \& Van Amelsvoort JM (1997) The effect of ingestion of inulin on blood lipids and gastrointestinal symptoms in healthy females. Br J Nutr 78, 215-222.

32. Nappo F, Esposito K, Cioffi M, et al. (2002) Postprandial endothelial activation in healthy subjects and in type 2 diabetic patients: role of fat and carbohydrate meals. I Am Coll Cardiol 39, $1145-1150$.

33. Rogers TS, Demmer E, Rivera N, et al. (2017) The role of a dairy fraction rich in milk fat globule membrane in the suppression of postprandial inflammatory markers and bone turnover in obese and overweight adults: an exploratory study. Nutr Metab 14, 36.

34. Trumbo P, Schlicker S, Yates AA, et al. (2002) Dietary reference intakes for energy, carbohydrate, fiber, fat, fatty acids, cholesterol, protein and amino acids. J Am Diet Assoc 102, 1621-1630.

35. Baecke JA, Burema J \& Frijters JE (1982) A short questionnaire for the measurement of habitual physical activity in epidemiological studies. Am J Clin Nutr 36, 936-942.

36. Berthelot CC, Kamita SG, Sacchi R, et al. (2015) Changes in PTGS1 and $A L O X 12$ gene expression in peripheral blood mononuclear cells are associated with changes in arachidonic acid, oxylipins, and oxylipin/fatty acid ratios in response to omega-3 fatty acid supplementation. PLOS ONE 10, e0144996.

37. Pfaffl MW (2001) A new mathematical model for relative quantification in real-time RT-PCR. Nucleic Acids Res 29, e45.

38. Masson CJ \& Mensink RP (2011) Exchanging saturated fatty acids for $(n-6)$ polyunsaturated fatty acids in a mixed meal may decrease postprandial lipemia and markers of inflammation and endothelial activity in overweight men. J Nutr 141, 816-821.

39. Bourlieu C, Cheillan D, Blot M, et al. (2018) Polar lipid composition of bioactive dairy co-products buttermilk and butterserum: emphasis on sphingolipid and ceramide isoforms. Food Chem 240, 67-74.

40. Sadur CN \& Eckel RH (1982) Insulin stimulation of adipose tissue lipoprotein lipase. Use of the euglycemic clamp technique. J Clin Invest 69, 1119-1125.

41. Esposito K, Nappo F, Marfella R, et al. (2002) Inflammatory cytokine concentrations are acutely increased by hyperglycemia in humans: role of oxidative stress. Circulation 106, 2067-2072.

42. Vors C, Pineau G, Drai J, et al. (2015) Postprandial endotoxemia linked with chylomicrons and lipopolysaccharides handling in obese versus lean men: a lipid dose-effect trial. J Clin Endocrinol Metab 100, 3427-3435.

43. Laugerette F, Vors C, Géloën A, et al. (2011) Emulsified lipids increase endotoxemia: possible role in early postprandial low-grade inflammation. J Nutr Biochem 22, 53-59.

44. He J, Wang C, Zhu Y, et al. (2016) Soluble epoxide hydrolase: a potential target for metabolic diseases. J Diabetes 8, 305-313.

45. Morisseau C \& Hammock BD (2013) Impact of soluble epoxide hydrolase and epoxyeicosanoids on human health. Annu Rev Pharmacol Toxicol 53, 37-58.

46. Norwood S, Liao J, Hammock BD, et al. (2010) Epoxyeicosatrienoic acids and soluble epoxide hydrolase: potential therapeutic targets for inflammation and its induced carcinogenesis. Am J Transl Res 2, 447-457.

47. Luria A, Bettaieb A, Xi Y, et al. (2011) Soluble epoxide hydrolase deficiency alters pancreatic islet size and improves glucose homeostasis in a model of insulin resistance. Proc Natl Acad Sci U S A 108, 9038-9043. 
48. Millán J, Pintó X, Muñoz A, et al. (2009) Lipoprotein ratios: physiological significance and clinical usefulness in cardiovascular prevention. Vasc Health Risk Manag 5, 757-765.

49. Hadaegh F, Hatami M, Tohidi M, et al. (2010) Lipid ratios and appropriate cut off values for prediction of diabetes: a cohort of Iranian men and women. Lipids Health Dis 9, 85.

50. Laugerette F, Alligier M, Bastard J-P, et al. (2014) Overfeeding increases postprandial endotoxemia in men: inflammatory outcome may depend on LPS transporters LBP and sCD14. Mol Nutr Food Res 58, 1513-1518.

51. Grandoch M, Feldmann K, Göthert JR, et al. (2015) Deficiency in lymphotoxin $\beta$ receptor protects from atherosclerosis in apoE-deficient mice. Circ Res 116, e57-e68.

52. Lo JC, Wang Y, Tumanov AV, et al. (2007) Lymphotoxin $\beta$ receptor-dependent control of lipid homeostasis. Science 316, 285288. 